\title{
Autopoiesis and Open Access Repositories
}

\author{
Malgorzata Pankowska \\ University of Economics, Katowice-Poland
}

\begin{abstract}
In this paper the relevance of the theory of autopoiesis is discussed for understanding the evolution of open digital repositories. The autopiesis is a metaphor which explains three themes 1) how systems construct and maintain their own components 2) how the systems deal with changes that are destructive to their identity 3) how the system's organization and its identity are shaped. The theory draws attention to the dynamics that constitute the process of evolution, instead of focusing on the outcomes of the process of evolution. The ideas are illustrated by case studies of research community information systems that are autopoietic.
\end{abstract}

\section{Introduction}

The development of the information society and the widespread diffusion of information technology (IT) give rise to new opportunities for learning and research. Higher educational institutions have been using Internet and other digital technologies to develop and distribute education and research results for several years. However, much of that materials are locked up behind passwords with proprietary systems, unreachable for outsiders. The trend towards sharing software programmes (open source software) and research outcomes (open access publishing) seems to be strong and complemented by the trend towards sharing learning resources. The reasons for individuals and institutions to use, produce and share openly research results can be divided into basic technological, economic, social and legal drivers The technological and economic drivers include improved, less costly and more usefriendly information technology infrastructure, distributed software and hardware. Legal drivers are new licensing schemes that facilitate free sharing and reuse of content. Government-supported research institutions allow for free sharing and reuse of resources, assuming that open sharing speeds up the development of new learning resources, stimulates internal improvements, innovation and further reuses. In the paper, the digital repositories of open publications are considered as closed in certain aspects. The first part covers the analysis of the background of the theory of autopoiesis. Next, autopoiesis as information system metaphor is discussed and some examples are given. Thirdly, the discussion of supporting research community digital repositories as autopoietic systems is provided.

\section{The theory of autopoiesis}

The idea of autopoietic systems is assumed to be the theory of social systems understood as systems of communication that reproduce all their necessary, specific structures within their own self-referential closed processes [1]. Therefore, systems of research communications can also be theoretized as autopoietic systems in the sense that they generate their own components and structures within the ongoing flows of communication. In this paper, research publications are considered as communications constituting the autopoietic system.

Luhmann's social systems theory provides a comprehensive theory of modern society on the basis of a general theory of social systems conceived as systems of communications [2].

According to Bouncken "autopoiesis is the joint birth of knowledge across actors of the system alliance" [3]. Autopoiesis is formed by group cognition. Groups can be seen as collective actors with a specific set of mental models that lead to organizational learning. Luhmann adds that systems refer to themselves, they are self-referential [2].

In 1972, Maturana coined the term "Autopoiesis" combining "auto" (Greek self-) and "poiesis “ (Greek: creation, production) to name the phenomenon of inner self-reproduction [4]. Autopoiesis - is the ability of a system to generate its specific constitution - its components (structure) and their interplay (organization) - on its own [5]. Autopoiesis can only be achieved by the unity of the components and their specific organization. Autopoietic systems show a remarkable property in the way they interact with their environment: on the one hand building blocks and energy (including information) are exchanged with the environment, which characterizes them as open systems; on the other hand any functional mechanisms, the way the system processes, incorporates building blocks and responds to information are totally self-determined and cannot be controlled by interventions from the environment.

Autopoietic systems are said to be capable of self-referencing. Self-referencing systems are open systems that refer only to themselves in terms of 
their intentioned purposeful organizational behaviour. This does not mean that they do not interact with the environment since it relates only to their purposefulness. Relations with the environment are determined from within the system. An autopoietic system defines its own boundaries relative to its environment, develops its own code of operations, implements its own programmes, reproduces its own elements in a closed circuit, and lives according to its own dominant paradigms. When a system reaches what we might call autopoietic take off, its operations can no longer be controlled from the outside.

Autopoietic systems are self-producing in a way that they produce a network of processes that enables them to produce their own components. Autopoietic systems are systems that continually produce or create themselves in closed circular processes of production. They have no other purpose and if the dynamic circularity is interrupted then they disintegrate. Living systems are autopoietic - they are organized in such a way that their processes produce the very components which are necessary for the continuance of these processes. Systems which do not produce themselves are called allopoietic. Maturana and Varela also refer to human-created systems as heteropoietic [6]. In an autopoietic system, the components are designed to interact with each other in such a way as to continually produce and maintain them and the relationships between them. The core autopoietic ideas are specified in the three points. These describe a dynamic network of interacting processes of production, contained within and producing a boundary, which is maintained by the preferential interactions of its components. The key notions, especially when considering the extension of autopoiesis to non-physical systems, are the idea of production of components, and the necessity for a boundary constituted by the produced components [6]. Autopoietic systems are not defined as selfreplicating systems i.e. systems that can build replicas of themselves e.g. computer viruses.

Autopoietic systems are organisationally closed; therefore all its possible states of activity must always lead to or generate further activity within itself. All processes are processes of self-production - the system's activity closes in on itself. The systems do not primarily transform an input into an output except in the sense of transforming themselves into themselves. The outputs of the autopoietic system, which it produces, are its own internal components, and the inputs it uses are again its own components, the system is thus in a continual dynamic state of self-production. All the possible states that they can enter must conform to or maintain the autopoietic organisation, otherwise they will disintegrate. It may appear that the structure of an autopoietic system changes in relation to, or in response to, changes in its environment.

Autopoiesis is concerned with processes of production of the components which themselves constitute the system. It is essential to identify clearly what are the components of an autopoietic social system and what are its processes of production. For example, Carlsen and Gjersvik [7] applied an autopoiesis metaphor to analyze possible organizational uses of workflow technology. For them, an autopoietic system can be an information system as a subsystem of social systems that deal only with information and communication inside them. They consider an autopoietic information system as a set of relations between communicative events that reproduce new communicative events based on previous (stored) communication. The organization of the system are the relations between communicative events described through their semantics (meaning). The structure of the system are the means that are used to produce communication described through syntax. Interactional autopoietic information systems emerge and do not depend on previously stored communication, but on current interactions between communicative events.

Teubner has been the central proponent for interpretation of the legal system as an autopoietic entity. His work can be seen as the application of cybernetic principles to the ongoing debate among legal theorists concerning the status of law as either autonomous and self-referring or derivative of the sociocultural setting in which legal acts are realized [8].

In [9], Wikipedia is considered as selfproductive, self-organizing and self-referential knowledge system. It is well organized according to the above mentioned principles. Wikipedia is an ongoing work in which, in principle and in particular, older articles tend to be more comprehensive and balanced, while newer articles may contain significant misinformation. Unlike a paper encyclopedia, Wikipedia is continually updated, with the creation of articles on topical events within short periods of time. As a wiki, articles are never complete. Wikipedia is in constant process of self-production. The articles are continually edited and improved over time, and in general this results in an upward trend of quality, and a growing consensus over a fair and balanced representation of information. There is no systematic process of information gathering, so Wikipedia contains unexpected oversights and omissions. Some academic topics may not be presented widely, while others, very popular, are noticed as topics deeply considered.

The concept of organizational autopoiesis can help managers to understand the operations of their organizations better. Information systems in an organization seem to accept the autopoietic system 
way of development. Wikipedia is a unique example of knowledge system which ensures users content self-production and auto-references in an organized way. Simultaneously, many similar autopoietic systems can be identified in open source software development areas. Software applications developed there are recognized as autopoietic systems as well as Web 2.0 information systems belonging to the second generation of virtual communities. Taking into account the characteristics of an autopoietic system specified above, they are considered as developed to facilitate collaboration and information sharing among users. They do not refer to the updating Web technologies, but rather to changes in the usage of Web platform. End users have the opportunity to create open information systems i.e. ufopaedia.org, craigslist, dodgeball. Their infoproducts are applied for the creation of subsequent infoproducts in an ordered way.

Self-organization is the essential force in the process of organizational autopoiesis. If there is no self-organizing ability, there is no autopoiesis in organizations and they are not sustainable [10]. Selforganization arises when independent individuals cooperate to respond creatively and to reflect in a specific problem situation. Truex et al. argue that self-organization is not deterministic, rather a product of a constant social negotiation, continual change of work culture and decision processes where outcome stages arise from previous history and context [11]. This they specify as the dialectics of organizational autopoiesis. Self-organizations are continuously emergent, they are scalable and increase the volume of their components. Creators of self-organizing systems define preferred directions and norms for autopoietic organizations. But command-and-control is not a norm here. Selforganization is the formation of things without topdown directions. Self-organization is based on trust and good will. Self-organization is not identified with anarchy, if anarchy is understood as lack of order, but anarchy can be interpreted as lack of central authority and in a positive sense - autonomy and complexity.

Self-organizing systems hold the promise of addressing many challenges in large scale distributed systems, especially in reducing the need for human intervention for configuration, recovery from failures, and performance optimization. According to Whitaker [12] a self-organization has been used to refer to a variety of distinct attributes such as:

- self-creation ( meaning that a given system's origin is somehow determined by its character or the specific circumstances in which it occurs);

- self-configuration (meaning that the system determines the arrangement of its constituent parts);
- self-regulation (meaning that a given system actively controls the course of its internal transformations);

- self-steering (meaning that the system actively controls its course of activity within some external environments);

- self-maintenance (meaning that the system preserves itself, its form and its functional status over time);

- self-production;

- self-reference.

Taking into account further opportunities of information technology development, the distributed systems could regulate and manage themselves in the areas of configuration, fault, performance and security to achieve some user preferred objectives. Models of distributed computing define its properties as:

- self-configuration;

- self-optimization (the system parts constantly seek improvement to their performance and efficiency, and are able to adapt to changing environment without direct human input);

- self-healing - (the parts can automatically detect and recover from faults);

- self-protection (the system parts can automatically defend against attacks or isolate the attackers) [13].

\section{Open system development premises}

Openness in the technical domain is characterized by technical interoperability and functionality. Open standards are important since they make it possible for different software applications to operate together. The openness blurs the traditional distinction between the consumer and the producer, or among business organizations.

On the push side, it is perceived that if universities do not support the open sharing of research results and educational materials, traditional academic values will be increasingly marginalized by market forces. On the pull side, a number of possible positive effects from open sharing are put forward, such as: broader and faster dissemination, people involvement in the problem solving, rapid quality improvements and faster technical and scientific development. The free sharing of software, scientific results and educational resources reinforces societal development and diminishes social inequality.

According to Dargan, open systems offer a building block approach to development that makes effective use of commercial products and open systems are based on standards that define basic system building blocks and provide a foundation for reuse, interoperability and evolution [14]. The greatest challenge in designing an open software system is selecting which standards to use for an enterprise. Another challenge is finding suitable 
standards-compliant commercial products. The third challenge is choosing standards that keep pace with technology innovations.

Open source software must be delivered with source code included or easily available. The license of this software will not restrict others from distributing the code or modifications and derived works under the same terms. Generally, intellectual property (IP) covers three main branches - copyright (original artistic and literary works of authorship); patent (inventions of processes, machines, manufactures and compositions of matter that are useful, new and non-obvious) and trademark (commercial symbols) [15]. The copyright and patent acts provide protection for intellectual property against unauthorized use, theft and other violations of the rights granted by those statutes to the IP owner. According to Cronin, plagiarism is not a legal but an academic offence which may be punishable according the institution's regulation [16]. It may be a legal offence if there are intentions to benefit from it financially at the expense of the copyright owner. Since 1990s the open source software licensing is regulated by the activities of Open Source Initiative. The most important licenses are the General Public Licenses, the Lesser General Public License and the Berkeley Software Distribution (BSD) Licenses. Academics worldwide have started to use open licenses to create a space in the Internet - a creative commons - where people can share and reuse copyright material without fear of being sued. The Creative Commons (CC) license gives others permission to copy, distribute, display and perform the copyright work and derivative works based on it, but for non-commercial purposes only. If anyone wants to use the work for a commercial purpose they must do so in agreement with the right holders. However, there is no clear understanding of what constitutes commercial use. Another problem is the clause called "Share Alike", meaning that any company trying to exploit the author's work will have to make their added value available for free to anyone else.

Open access and commons are used interchangeably to refer to the situation in which a resources is accessible to all members of a community on nondiscriminatory terms, meaning specifically that terms do not depend on the users' identity or intended use. However, there difference between open access and commons is maintained. According to Frischmann [17], open access implies no ownership rights or property rights, no entity possesses the right to exclude others from the resource, so all who want access can get it. Commons, on the other side, involves some form of communal ownership (community property rights, public property rights, joint ownership rights). Intellectual property rights protection is supported by trust that can be defined as the expectation that the counterpart will behave in a reliable, predictable and fair manner, particularly when the potential for opportunism is presented. The dishonest behaviour is in Internet observed as plagiarism and autoplagiarism of research works.

Cyberscience presents a considerable potential to change the system of quality control. In particular, the new forms of ex post control, such as rating readers give marks to what they read - and usetracking - which items groups or readers have read, used or quoted is recorded and aggregated results are fed back to readers - are not feasible in the paperbased world of publishing [18]. The working-paper archives and journals seem to offer both ex ante and ex post peer commenting. Such interactive (as opposed to one-way) communication plays a significant role in most of the new formats of publication quality control. Peer review is considered to be the de facto standard approach to quality control. For many researchers peer review has a filtering role and helps to establish a hierarchy of journals and books. For others, reviews are done according to the individual preferences and competencies of reviewers. Bias or misunderstandings can be demonstrated on the part of reviewers. Peer review works as a helpful aid and researchers generally agree that peer review gives them some measure of confidence in the quality and value of a piece of work.

The openness of information system is the characteristic that determines whether the system can be extended and re-implemented in various ways. The openness of distributed systems is determined primarily by the degree to which new resourcesharing services can be added and be made available for use by a variety of client programs. Openness cannot be achieved unless the specification and documentation of the key software interfaces of the components of a system are made available to software developers. So the key interfaces are published. However, the publication of interfaces is only the starting point for adding and extending services in a distributed system. The challenge to designers is to tackle the complexity of distributed systems consisting of many components engineered by different people. Open distributed systems can be constructed from heterogeneous hardware and software, possibly from different vendors. But the conformance of each component to the published standard must be carefully tested and verified if the system is to work correctly.

Information resources that are made available and maintained in distributed systems have a high value to their users. Protection for information resources has two components:

- integrity (protection against alternation or corruption);

- availability (protection against interference with the means to access the resources).

The security of an open distributed system can be achieved by securing the processes and the channels 
used for their interactions and by protecting the objects that they encapsulate against malicious and destructive access.

\section{Open publication development processes}

Business organizations have begun to develop more open, interactive economic models, termed 'open business models', where the absorption of external resources for value creation is permitted and highly appreciated. Specifically, organizations look to leverage external knowledge resources that provide new ideas to an organization for creating new products and services. Open business models rely on a permeable organizational boundary, allowing the inflows and outflows of knowledge between the organization and its environment. The new open business model occurs when both organizations and clients as prosumers produce and provide value to each other through content contributions that create mutual benefits.

Lately, the concept of open government has been influenced by the open source software and permitted for participation in the procedures of government. Just as open source software allows users to change and contribute to the source code of the software, open government means government where citizens not only have access to information, documents and proceedings, but can also become participants in e-democracy processes.

Higher education faces many challenges i.e. globalization, an aging society in Europe, growing competition among higher educational institutions both nationally and internationally, and rapid technological development. The open educational resource movement aims to break down barriers and to encourage and enable freely sharing content [19].

Open educational resources are digitized materials offered freely and openly for educators, students and self-learners to use and reuse for teaching, learning and research. Open educational resources include learning content, software tools to develop, use and distribute content and implementation resources such as open licenses. However, there is an imbalance between the provision of open educational resources and their utilization. It should be noticed that the vast majority of open education resources is in English and based on Western culture. Expression of the teaching materials content only in one language and lack of the translation into other languages lead to the situation where researchers share their knowledge among one culture and many people do not have opportunity to learn and to utilize the knowledge.

Nowadays, researchers have plenty of opportunities to support open access and get greater reach for their research through open access journals, open access repositories and author rights management initiatives. In the science fields where book publishing is the dominant mode of communication and reputation building, publishers have a great deal of control over how those fields are represented and when, how and who can access research outcomes. Though technical standards are necessary for interoperability, there has been a resistance to data standards in many humanities fields because they are perceived as necessitating the standardization of research objects and imposing a normative practice. In human sciences, there is a low-degree of functional dependence and the values and goals incorporated in the technologies of one field are less likely to be shared by another. In physical sciences (e.g., physics, high-energy physics), the knowledge is cumulative, atomistic, concerned with universals, guaranties, simplification, resulting in discovery and explanation. The research works are politically well organized, high publishable and task-oriented. In humanities (e.g., history, linguistics) and pure social sciences (e.g., anthropology, geography), the knowledge is reiterative and concerned with particulars, qualities and resulting in understanding and interpretation. The research works are pluralistic, loosely structured, person-oriented and characterized by low publication rate. In applied sciences (e.g., mechanical engineering), the purposive and pragmatic knowledge is concerned with mastery of physical environment and resulting in products and techniques. The research works are entrepreneurial, dominated by professional values and role-oriented. Patents substitute for publications. In social sciences (e.g., education), the functional and utilitarian knowledge is concerned with enhancement of professional practices and resulting in protocols and procedures. The research works are uncertain in status, dominated by intellectual fashions and poweroriented. Publication rates are reduced by consultancies.

The fields of science have different attitudes towards publishing processes and e-science is differently understood in the particular disciplines. Generally, e-science is defined as the combination of three different developments: the sharing of computational resources, distributed access to massive data sets and the use of digital platforms for collaboration and communication [20]. This is accomplished by transferring the entire research process into the digital environment.

The creation of European collaboration and communication networks in science and scholarly research is one of the key elements of the European Research Area. This means that collaboration and connectivity indicators need to be developed further than they are at present. Scientific collaboration networks i.e. research grids, are constructed to support academic and research community. Some of the notable examples include: 
- Turgid (http://www.teragrid.org),

- EGEE (http://public.eu-egee.org),

- LA Grid (http://latinamericangrid.org),

- and D-Grid (http://www.d-grid.de/).

Many different grids have emerged in the last decade. EGEE (http://public.eu-egee.org) is used among the European scientific community. BOINC (http:// boinc.berkeley.edu/) is an open-source software platform for computing using volunteered resources. XtremWeb (http://www. xtremweb. net/) is an open source software to build lightweight Desktop Grid by gathering the unused resources of desktop computers (CPU, storage, network). Nowadays, the grid projects provide access to the open repository of research databases and publications, and they create the opportunity to utilize open source software as well as ensure epublications on projects' deliverables. The open access movement as the worldwide effort was initiated by other organizations to provide free online access to scientific and scholarly research literature, especially peer-reviewed journal articles and their preprints. The open access movement started out with a series of statements and declarations:

- Budapest Open Access Initiative (BOAI);

- Bethesda Statement on Open Access Publishing;

- Berlin Declaration on Open Access to Knowledge in the Science and Humanities.

Open access means the permission for any user to read, download, copy, distribute, print, search or link to the full texts of the articles, crawl them for indexing, pass them as data to software for processing and use them for any lawful purpose. Open access repositories are organized as a place to share and exchange knowledge resources, which means that people are either users or producers, or they can promote the collaborative production of common resources. The number of open access repositories increases. The excellent examples are as follows:

- arXiv.org (Los Alamos, USA);

- CogPrints (University of Southampton, UK);

- The Networked Computer Science Technical Reference Library (NCSTRL);

- RePEc (the University of Manchester, UK);

- EconWPA (Washington University, USA);

- Networked Digital Library of Theses and Dissertations (NDLTD - Virginia Tech, USA);

- CERN Document Server (Geneva, Switzerland);

- Internet Archive;

- Public Library of Science;

- BioMed Central;

- Google Book Search;

- Gutenberg Project;

- Harvard University;

- MIT Open Course Ware;

- OpenEdition.

OpenEdition (http://www.openedition.org/) is the academic community offering three international platforms in the humanities and social sciences: Revues.org, Calenda, Hypotheses.org for open access publicized documents. The other worldwide initiative includes EBSCO A-to-Z® Web-based tool, DOAJ, Bentham Science, OpenDOAR. Mentioned above arXIv.org is an international initiative and has mirror sites in 13 countries and collaborates with US and foreign professional societies. It provides a crucial service line for isolated researchers in developing countries. As a public service, arXiv should be supported by those institutions that use it the most. There is a list of the most active 200 institutions, based on download data. However, there are no precise statistics based on articles submitted to arXiv. This is because arXiv does not demand for submitters to include affiliation information for authors and does not control any affiliation metadata that is submitted. $\quad$ EBSCO A-to- ${ }^{\circledR}$ (http://atoz.ebsco.com/) is the industry's most complete Web-based tool for organizing and providing links to all of a library's e-resources, including e-journals, titles in full-text databases, ejournal packages, and e-books. The Directory of Open Access Journal (DOAJ) (http://www.doaj.org/) developed and maintained by Lund University Libraries and the e-Depot of the National Library of the Netherlands (KB) have started a cooperation in order to secure long-term preservation of open access journals. The Swedish Library Association is generously acting as sponsor. The aim of the DOAJ is to increase the visibility and ease of use of open access scientific and scholarly journals thereby promoting their increased usage and impact. Currently, the DOAJ collection covers about 4000 journals and is characterized by a very large number of publishers $(2.000+)$, each publishing a very small number of journals on different platforms, in different formats and in more than 50 different languages. Bentham Science is a major journal publisher of 92 online and print journals, over 200 open access journals and related print and online book series. Bentham Science answers the informational needs of the pharmaceutical, biomedical and medical research community. OpenDOAR (http://www.opendoar.org/) is an authoritative directory of academic open access repositories. Each OpenDOAR repository has been visited by project staff to check the information that is recorded there. This in-depth approach does not rely on automated analysis and gives a qualitycontrolled list of repositories. OpenDOAR aims to provide a quality assured list of academic repositories containing full-text materials that are openly accessible.

Open access repositories increasingly play a pivotal role in the emerging research information landscape. Repositories are being deployed in a variety of environments (education, research, science, cultural heritage) and contexts (national, 
regional, institutional, project, lab, personal). They are operating across administrative and disciplinary boundaries and interact with distributed computational services and social communities. Institutions such as universities, research laboratories, publishers, libraries and commercial organizations are creating innovative repositorylinked systems for management of digital content to enable use, reuse and interconnection of information.

The issue of who pays for open access articleprocessing charges is still being discussed. Some commercial publishers and a number of universities are now experimenting with an open access book publishing model, providing free online access and paid-for hard copies, printed-on-demand. The business models of funding the publications cover the following solutions:

- user-producer model: centralized model, although real costs can be met with resources other than money, most initiatives need to raise some capital;

- the replacement model, where open content replaces other usage and benefits from cost savings;

- the donation model, in which founding is provided by external actors;

- the segmentation model, in which something is given to the customer (i.e. reader) for free to convert the consumer to a paying customer;

- membership model, based on fund-raising campaigns or paying members.

In Figure 1, the business process model covering publishing activities is presented.

\section{R\&D Institutions}

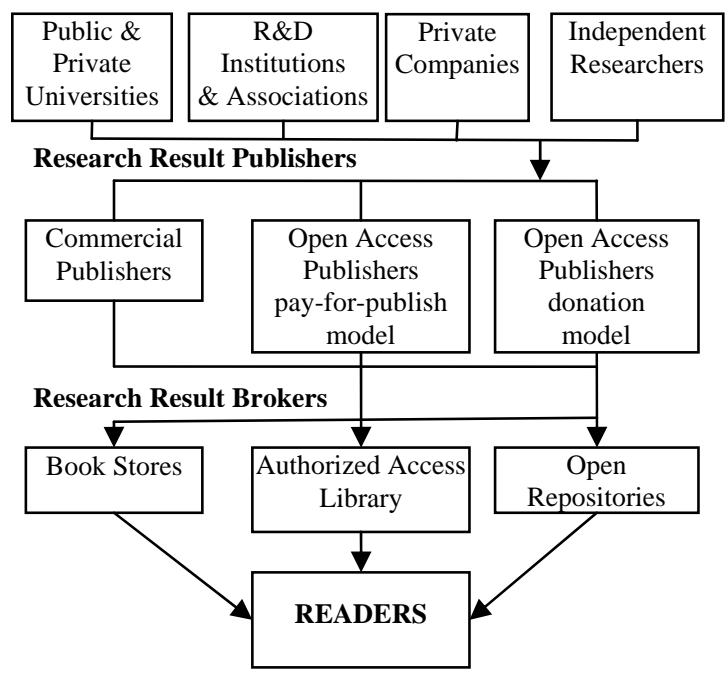

Figure 1. Open access publication development process

Generally, research works are conducted by research and development (R\&D) units, universities and private companies. In the model, category of independent researchers is identified, who are not affiliated to any institutions. Research results are published by commercial publishers as well as by fully or partly open access organizations. Open access publishers are sponsored by individuals (payfor-publish approach) or institutions (donation approach), therefore the open repositories can offer publications free of charge to the readers. Simultaneously, publications' market is supplied by commercial publishers, who sell books and journals to book stores and authorized access libraries.

The community consisting of research institutions, publishers, stores and repositories is an autopoiesis i.e. a self-productive and self-referencing system, which constantly renews earlier theories and models, discoveries and inventions. The community is self-supported and in the aspect of realized research and science domain is a closed community. Acting in and for the community demands achieving a certain level of expertise, understanding and interpretations, otherwise openly accessible publications are not understandable and useless.

On one hand, the Internet and the new digital technologies are allowing an unprecedented way of accessing and distributing information. On the other hand, technological protection measures designed to enforce intellectual property rights (IPRs) in digital environments threaten fundamental exceptions in copyrighted laws for disabled people, libraries, educators and undermine privacy and freedom. To guarantee access to online publications and to copyrighted material representatives from the copyright-based industries are suggesting special initiatives such as donation schemes and low price editions of books, as the way to go instead of the weakening of international copyright rules or national IPRs enforcement rules in developing countries. However, the approach will create further technological lock-in for the less developed countries because of lack of investment in research. The system is open for people who understand knowledge, otherwise the openness does not guarantee that the knowledge and the content of the stored documents is understood. Open repositories are open only for the educated, so at first and foremost the investments in education and research to avoid exclusion, to support e-Inclusion must be made

In the traditional view, knowledge is a representation of a pre-given reality, universal, objective and transferable. In autopoietic system of open publications, knowledge is created and based on distinction making in observation, is history dependent and context sensitive, transferable as renewed and changed. The new publications are the products of the previous ones. The self-referential knowledge creation evolves as individual and group experiences are interpreted and renewed. Autopoiesis is beyond the cognition at the individual level. The autopoietic system of open publications includes potential future knowledge as well as past knowledge. The joint generation of knowledge in the 
autopoiesis emerges from knowledge that is attributed to a specific context (e.g., a technology, group, firm or alliance). The location of the collective knowledge in autopoiesis differs from absorption, in which actors learn from each other by exchanging parts of their thoughts. Autopoiesis covers the collective repository of knowledge and research publications across scientific institutions. Autopoiesis of open publications is manifested by a web of upstream, downstream and horizontal exchanges and interactions. It requires individuals to interactively (i.e. personally or through the publication communications) produce mental models.

In open access publication systems, like in any other self-organizing system, none of the publication providers can fully understand the entire system. That is why they must standardize their mode of providing publications. Control must be delegated and distributed over all team members. The control of the entire repository is based on respecting the general rules and the collaborative efforts allowing the system to sustainably develop.

\section{Conclusion}

The metaphor of autopoiesis opens up an interesting and alternative perspective on how virtual communities evolve. It provides a view of information systems as social systems of interaction or social web, which continuously try to maintain their image of research community serving repository. In the theory of autopoiesis, the identity of system plays a central role and is continuously reproduced through the mechanism of autopoiesis. In contrast to common perspectives on the evolution of information systems the emphasis is not on the successive outcomes, but on the underlying processes that generate these outcomes.

The research community as a distributed information system constitutes itself as an autonomous and organizationally closed system aiming at the continuance of its production and reproduction of publications.

The research community continuously organizes itself. The system enacts its environment by distinguishing only those aspects that make sense to the system, and it tends to ignore all that does not make sense to the system. The system is continually maintained and reinforced through self-referential processes of research and knowledge creation.

Autopoiesis, when used as a metaphor, may provide an interesting perspective on the process of evolution of research community information systems. The interesting insight the approach offers is that the main aim of the system is to maintain their identity of knowledge repository, The community evolution is determined by the identity its information system has gained. Consequently, the evolution of research community can be characterized as self-referential, autonomous and organizationally closed.

\section{References}

[1] Schumacher, P.S., The Autopoiesis of Architecture: A New Framework for Architecture, J.Wiley and Sons, Chichester, 2011

[2] Luhmann, N., Social Systems, Stanford University Press, Stanford,1995.

[3] Bouncken, R., Autopoiesis: the conception of joint learning, European Journal of Management, Winter 2008, Vol 8 Issue 4; http://www.freepatentsonline.com/article/EuropeanJournal-Management/190617047.html (22 July 2011).

[4] Thannhuber, M.J., The Intelligent Enterprise, Theoretical Concepts and Practical Implications, Physica-Verlag, A Springer Company, Heidelberg, 2005.

[5] Yolles, M., Management systems, a viable approach, Financial Times, Pitman Publishing, London, 1999.

[6] Mingers, J., Realising Systems Thinking, Knowledge and Action in Management Science, Springer Science, Business Media, NY, 2006.

[7] Carlsen, S., Gjersvik, R., Organizational Metaphors as Lenses for Analyzing Workflow Technology, ACM SigGroup GROUP'97, Conference, Phoenix Arizona, November, 1997; http://citeseerx.ist.psu.edu (22 July 2011).

[8] Teubner, G., (ed.), Autopoietic Law: A New Approach to Law and Society, Walter de Gruyter, Berlin / New York, 1988.

[9] Pankowska, M., Autopoiesis in virtual organizations, Advanced Information Technologies for Management - AITM 2007, Korczak, J., Dudycz, H., Dyczkowski, M., (eds.), Research Papers No 8 (1208) Wroclaw University of Economics, Publishing House of the Wroclaw University of Economics, Wroclaw, 2007, pp.102-111.

[10] Dimitrov, V., Fell, L., Autopoiesis in organizations, 2007; http://www.pnc.com.au/ lfell/vlad3.html (10 December 2007)

[11] Truex, D., Baskerville, R., and Klein, H., Growing Systems in Emergent Organizations, Communications of the ACM, August, 1999, Vol.42 No 8., pp. 117-123.

[12] Whitaker, R., Self-Organization, Autopoiesis and Enterprises, 1995; http://www710.univlyon1.fr/ jmathon/autopoesis/Main.html (22 July 2011).

[13] Boutaba R., Xiao J.: An Introduction to Network and Service Management, Handbook of Enterprise Integration, Sherif, M.H, (eds.), CRC Press, Auerbach, Boca Raton, 2010, pp.159-184.

[14] Dargan, P.A., Open systems and standards for software product development, Artech House, Boston, 2006.

[15] Yeh, B.T., Intellectual Property Rights violations: Federal Civil remedies and criminal penalties related to Copyrights, Trademarks and Patents, CRS Report for Congress, 2008; http://www.fas.org/sgp/crs/misc/RL34109.pdf (10 January 2010). 
[16] Cronin, C., Plagiarism, copyright, Academia and Commerce, presentation given at Colby College in Proceedings of the Conference on Information Ethics and Academic Honesty, 2003; http://abacus.bates. edu/cbb/ docs/ Cronin.pdf (1 March 2011).

[17] Frischmann, B.M., Infrastructure Commons in Economic Perspective, Internet Policy and Economics, Lehr, W.H., Pupillo, L.M. (eds.), Springer Berlin, 2002, pp.29-57.

[18] Hine, Ch.M., New Infrastructures for Knowledge Production, Understanding e-Science, Information Science Publishing, Hershey, 2006.

[19] Giving Knowledge for Free, The emergence of open education resources, Centre for educational research and innovation, Organisation for economic cooperation and development, OECD, Paris, 2007, http://www.oecd.org/bookshop/, (1 March 2011).

[20] Hey, T., Trefethen, A.E., The UK e-Science Core Programme and the Grid, Future Generation Computer Systems, 2002, 18(8), pp.1017-1031. 